\title{
LOS ORÍGENES (TARDÍOS) DE LA LEXICOGRAFÍA BILINGÜE ESPAÑOL-PORTUGUÉS
}

\author{
IGNACIO VÁZQUEZ \\ Universidad de Barcelona \\ ivazquez@ub.edu
}

\begin{abstract}
Bilingual lexicography between western European languages first appears in the $16^{\text {th }}$ century. This however, is not the case with Spanish and Portuguese. Portugal gave precedence to the dictionaries which included Portuguese and the languages of its colonies. This fact coupled with the Portuguese socio-linguistic situation caused a delay in the appearance of dictionaries where Portuguese appeared alongside other European languages. It is interesting to note that before the $19^{\text {th }}$ century there did not exist a Spanish/Portuguese dictionary. The first such dictionary, published in Lisbon, dates from 1864: Diccionario EspañolPortuguez by Mascarenhas Valdez. The appearance of this dictionary, after a period of dissociation between Spain and Portugal, reflects the ideas of Iberismo.
\end{abstract}

KEYWORDS: lexicography, bilingual, Spanish, Portuguese, history.

\begin{abstract}
Resumen
La lexicografia bilingüe entre las lenguas europeas occidentales aparece en el siglo XVI. No es el caso, sin embargo, del par español-portugués. Portugal dio prioridad a los diccionarios que confrontaban el portugués y las lenguas de sus colonias. Este hecho y la situación sociolingüística portuguesa produjeron una demora en la aparición de obras lexicográficas donde el portugués aparecía junto a otras lenguas de Europa. Es sorprendente que entre español y portugués no haya ninguna obra anterior al siglo XIX. El primer diccionario, publicado en Lisboa, data de 1864: el Diccionario Español-Portuguez de Mascarenhas Valdez. La aparición de tal obra responde, tras un período de alejamiento entre España y Portugal, a las ideas renovadoras del Iberismo.
\end{abstract}

PALABRAS CLAVE: lexicografía, bilingüe, español, portugués, historia.

\section{Introducción}

Como es sabido, la lexicografía bilingüe producida entre las diversas lenguas europeas documenta en el siglo XVI sus primeros diccionarios'. No obstante, esa afirmación no es aplicable al portugués, que conoce una producción en dicho campo diferente, por ejemplo, al español, francés, italiano, inglés o alemán. En realidad el portugués comienza a representarse en diccionarios de la misma índole solamente a partir del siglo XVIII2.

1 Véanse los estudios pormenorizados que desarrollan Dolores Azorín en el capítulo segundo de Los diccionarios del español en su perspectiva histórica, Alicante, Universidad de Alicante. (Monografías), publicado en 2002 y José Joaquín Martínez Egido en La Lexicografia bilingüe y plurilingüe de los siglos XVI y XVII. E-Excellence: Lengua española, Liceus, Madrid (2006) [htpp://www.liceus.com/cgi-bin/aco/len/temas_II.asp\#lexicologia]. Del mismo autor destaca la tesis doctoral La obra lexicográfica de Lorenzo Franciosini : vocabulario italiano-español, español-italiano (1620), del año 2002, disponible en [www.cervantesvirtual.com] donde se estudia la cuestión.

2 Stefan Ettinger apunta algunas ideas sobre la lexicografia bilingüe portuguesa en "Die zweisprachige Lexikographie mit Portugiesisch", en Wörterbücher: Ein internationales Handbuch zur Lexicographie/Dictionaries: An international Encyclopaedia of lexicography/Dictionnaires: Encyclopédie internationale de lexicographie, Haus- 
Es probable que debido a las propias circunstancias históricas portuguesas, en sus inicios, la lexicografía portuguesa mostrase más interés en producir diccionarios que confrontaban el portugués con las lenguas asiáticas o africanas con las que Portugal había tomado contacto político desde los siglos de la expansión ultramarina y los posteriores procesos de colonización. Con todo, no deja de ser sorprendente que el primer diccionario bilingüe entre español y portugués se publique en Lisboa sólo en 1864, fecha ciertamente tardía para el primer diccionario bilingüe entre dos lenguas europeas próximas. Se hace necesario reflexionar sobre la propia lexicografía portuguesa (cuando no sobre la historia portuguesa) para entender el motivo de esa demora.

Para empezar, la siguiente cita de Manuel Alvar Ezquerra (1995:188), extensa, puede aportar alguna luz a la cuestión:

Frente a lo que ocurre con otras lenguas románicas como el italiano o el francés, o con el inglés, el nacimiento de la lexicografĩa bilingüe hispano-lusa es ciertamente tardía. La justificación de este hecho habría que buscarla por dos caminos diferentes: por un lado, la proximidad geográfica y, sobre todo, lingüística de ambos idiomas no hacía necesario un medio para facilitar la comunicación como es el diccionario. Es más, la historia de nuestra literatura ha visto de manera constante autores que escribían indistintamente en una lengua o en otra. Por otra parte, la falta de los repertorios bilingües se cubría con aquellas obras plurilingües que contenían el español y el portugués. Baste con recordar que el español aparecía como lengua complementaria en la Prosodia in vocabularium trilingue de Bento Pereira.

El más antiguo de los diccionarios bilingües con el español y el portugués no aparece hasta la segunda mitad del siglo XIX, fecha ciertamente tardía para que ocupe un lugar preeminente en la historia de nuestros diccionarios. Es el de Manuel do Canto e Castro Mascarenhas Valdez, Diccionario español-portugués el primero que se ha publicado con las voces, frases, refranes y locuciones usadas en España y Américas Españolas (Lisboa, 1864-1866).

\section{Antecedentes del Diccionario Español-Portuguez de Mascarenhas Valdez}

A lo largo de los siglos XVI y XVII la lexicografía multilingüe compilaba en diccionarios - alguno tardíamente en el XVIII - diferentes lenguas europeas en las que siempre aparecía el latín como lengua puente entre ellas. Dichas obras, en mayor o menor medida, acogían al español y al portugués pudiendo haber servido para el cometido comunicativo en este par que nos interesa. De producción autóctona, surge en Portugal, como apunta arriba Alvar Ezquerra el Prosodia in vocabularium trilingue, Latinum, \& Hispanicum de Bento Pereira en 1634.

El mismo autor en 1661 publicó el mismo diccionario cambiando el adjetivo Hispanicum por Castellanicum (Prosodia in vocabularium trilingue, Latinum, Lusitanicum, et Castellanicum). Posteriormente, a partir de 1683 la obra pasó a ser bilingüe latín-portugués, desapareciendo la lengua española: Prosodia in vocabularium bilingüe latinum et lusitanicum.

mann, Reichmann, Wiegand y Zgusta [eds.], 3 volúmenes, Berlín y Nueva York, De Gruyter, págs. 3.020-3.030, 3r volumen, (1989-1991). Nos dice que la lexicografia portugués/lengua de la Europa central no aparece hasta el siglo XVIII, para lenguas escandinavas hasta el XIX y las eslavas en el XX. Enumera una gran cantidad de diccionarios de los siglos XVI, XVII y XVIII con lenguas asiáticas. Destacan los diccionarios multilingües. Se entiende que Portugal hiciese diccionarios con lenguas asiáticas debido a su imperio colonial en Asia, pero no se percibe que desatendiese a las lenguas europeas y, concretamente al castellano, lengua de prestigio internacional de la época a la que nos referimos, a la par que lengua presente en su territorio. 
Creemos que se hace necesario ante estos datos comentar algunos aspectos: en primer lugar, el diccionario de Bento Pereira, aun en sus ediciones trilingües da muy poca importancia al castellano, los equivalentes en nuestra lengua aparecen en voces diseminadas, no en todo el lemario. La obra es eminentemente un vocabulario latino con explicaciones de los lemas en portugués y, en ocasiones, la equivalencia española. De todos modos, conoció varias ediciones y ello puede indicar que funcionaba con éxito, por lo menos en el ámbito portugués.

En segundo lugar, el hecho de que en una edición posterior se cambiase 'hispanicum' por 'castellanicum' indica un factor de tipo social: hasta la recuperación de la soberanía portuguesa en 1640 tras el período en que España reinó en Portugal, se entendía por hispánico el conjunto de toda la Península. Una vez separados los dos reinos, el ideal nacional portugués comenzó a diferenciar en lo referente a España y su lengua oficial, y comenzó a utilizarse castellano como diferente de hispánico.

Sea como fuere, no hay ninguna obra más de las características que nos interesan hasta la aparición del Vocabulario Portuguez e Latino de Raphael Bluteau (1712-1721). El volumen octavo y último, aparecido en 1721 incluye una "Prosopopeia del idioma portuguez a su hermana la lengua castellana" y un pequeño vocabulario muy elemental portugués-castellano que parece justificar las palabras vertidas en la 'Prosopopeia', más que servir de apoyo real al aprendizaje de la lengua. Con la retórica propia del siglo XVIII Bluteau encomienda a sus vecinos españoles a que aprendan la lengua portuguesa defendiendo que son iguales en prestigio, que ambas vienen del latín y no la lengua portuguesa de la española, idea bastante extendida entre algunos gramáticos de siglos precedentes. Todas estas ideas vienen a corroborar una vez más la situación sociolingüística en que se encontraba Portugal durante y tras la época de dominio español.

Y por fin, entre 1864 y 1866 se publicó en Lisboa el Diccionario Español-Portugués el primero que se ha publicado con las voces, frases, refranes y locuciones usadas en España y Americas Españolas, en el lenguaje comun antiguo y moderno, las ciencias y artes de medicina, veterinaria, quimica, mineralogia, historia natural y botanica, comercio y nautica, con algunos nombres propios, y asi las voces particulares de las Provincias Españolas y Americanas, etc. compuesto sobre los mejores diccionarios de las dos naciones por Manuel do Canto e Castro Mascarenhas Valdez Hidalgo Caballero de la Casa Real en la Imprenta Nacional.

A partir de este diccionario y hasta la actualidad, la producción de diccionarios bilingües con el par español-portugués y viceversa es imparable. Pero queremos retomar una cuestión primordial que ha ido planeando sobre nuestro discurso: el porqué de la tardía aparición de la lexicografia bilingüe entre el español y el portugués y viceversa.

\section{Justificación ante la tardía aparición de la lexicografía bilingüe E/P}

Todo parece arrancar de la situación sociolingüística que vivió Portugal durante los siglos XV a mediados del XVIII: el bilingüismo (literario y científico) practicado por la clase alta. Dicho bilingüismo alcanza su punto culminante durante la época de 1580 a 1640, etapa conocida como Monarquía Dual o Filipina, ya que reinaron ambos países tres Felipes de la Casa de Austria: Felipe II, III y IV. No obstante, el español ya se había introducido en Portugal mucho antes, en el siglo XV. ¿Por qué? 
Dicha pregunta es de complicada respuesta. Muchos han sido los estudios que se han publicado, tanto del lado portugués como del español, para intentar explicar la presencia de la lengua española en Portugal durante ese período. Los factores políticos podrían haber sido determinantes y entendibles, pero la cuestión sobrepasa la política ${ }^{3}$. El influjo de la lengua española en esos dos siglos y medio en la corte portuguesa y su cultura hizo peligrar la posición del portugués como lengua de cultura en su propio país.

Dicha cuestión ha sido ampliamente estudiada porque repercutió en la literatura, en la idiosincrasia de muchos literatos, en el ideario lingüístico de bastantes gramáticos portugueses y, socialmente, propició cierta animadversión entre los dos países.

En el ámbito lingüístico y, concretamente, en el lexicográfico parece que provocó la inexistencia de una lexicografía bilingüe entre las dos lenguas. En los primeros tiempos porque el español utilizado por los literatos portugueses era, realmente, una koiné aprendida de unos escritores a otros -el diccionario era, por tanto, innecesario, más si tenemos en cuenta que los diccionarios no se usaban para la lengua oral sino la escrita--, después, una vez que Portugal volvió a ser independiente, por el alejamiento, por la desconfianza ante todo lo español.

Veamos los antecedentes históricos que propiciaron esta situación.

\subsection{El Humanismo. Preponderancia del latín como lengua de cultura frente al portugués}

Durante los siglos XV y XVI, la cultura europea experimentó una profunda mudanza con respecto a la Edad Media, el Renacimiento. El clasicismo greco-latino, cuyo conocimiento se restaura informa de esa mudanza. La aparición de la imprenta, los descubrimientos geográficos ultramarinos y el desarrollo económico y de las ciudades provocaron el advenimiento del mundo moderno.

La Iglesia también padeció esos excesos terrenales y muy pronto se vio contaminada del poder político y la atracción del lujo. Para contrarrestar esos comportamientos, ajenos al Cristianismo de los primeros tiempos, se inició en el norte de Europa la llamada Reforma protestante, apoyada por intereses políticos -intereses estos adeptos a los nuevos valores renacentistas-. El Papado adquirió tanto poder en este cometido que en poco tiempo se instauró como una verdadera fuerza política en Europa; dicho proceso se conoce como Contrarreforma. España y Portugal fueron los dos países de la Europa del sur libres de la influencia del protestantismo y en poco tiempo se erigieron como estandartes de la Iglesia Católica. El ideal de unidad religiosa se percibía en los literatos que utilizaban el término hispánico y España para englobar a todos los pueblos de la Península Ibérica.

Respecto a las letras (Humanismo), por toda Europa se desarrollaban los estudios clásicos, con un vehículo privilegiado, el latín, utilizado según los cánones de los grandes autores romanos. La literatura tiende a refinarse, sufriendo influencia de los autores griegos y latinos, cada vez más leídos y apreciados. La propia lengua escrita pasa por un severo proceso de latinización, sofisticándose a lo largo de los siglos XV y XVI. Al tiempo que se elevan las lenguas vulgares a lenguas de cultura, el latín se retoma como lengua de la

3 El 12 de noviembre de 1582 el rey Felipe II firmó una 'Carta patente' en Lisboa donde se establecía un compromiso para el uso oficial de la lengua portuguesa en la correspondencia regia y en los diplomas referentes a Portugal. Por tanto, parece que no se impuso políticamente el castellano en el reino portugués. 
erudición y de la investigación. En España su importancia fue grande como elemento de cultura y unión con los valores renacentistas del nuevo orden instaurado, sin embargo, en Portugal, su uso fue casi exclusivo.

En ese ideal por acercarse a las obras de los clásicos, su traducción a las lenguas vernáculas presentaba una serie de dificultades que hicieron reflexionar a los escritores sobre la lengua que aspiraban a ilustrar. En el caso de España, en 1492 se publicó la Gramática de la lengua castellana de Antonio de Nebrija, primer gran intento de sistematizar una lengua románica. Como apunta Lapesa (1986:288):

El concepto de 'artificio' o 'arte', esto es, regulación gramatical, estaba reservado a la enseñanza de las lenguas cultas, esto es, latín y griego; era una novedad aplicarlo a la lengua vulgar, pues se creía que, aprendida de los labios maternos, bastaban la práctica y el buen sentido para hablarla debidamente.

No obstante, el Renacimiento no sólo pretendía volver hacia la Antigüedad, sino también exaltar los valores propios de las nuevas naciones, así se rehabilitó el uso de las lenguas vulgares. Surgieron obras en defensa de las lenguas autóctonas en Francia, Italia, España y Portugal. En ese período se estandarizaron gráficamente los idiomas, no obstante, el caso portugués guarda unas particularidades específicas. En el ambiente del Humanismo surgieron las primeras gramáticas (Oliveira, 1536; Barros, 1540) que eran vistas como elementos de valoración de la lengua vulgar como lengua de cultura que se distanciaba de la escolástica de la Iglesia (cuya esfera del saber escrito se expresaba en latín). Pero esa unidad lingüística al servicio de la unidad nacional y de la expansión ultramarina se vio truncada, como ya hemos afirmado, por la acción de la Contrarreforma. La Iglesia detuvo el proceso de normativización de la lengua portuguesa. El establecimiento definitivo del Tribunal de la Santa Inquisición en 1547 censuró toda la producción científica y literaria escrita en portugués, ya que en ese contexto, el valor dado a las lenguas vulgares era sinónimo de herejía por incitar al protestantismo. El Concilio de Trento (1564) intensificó la represión intelectual. Portugal fue el único país donde las decisiones del Concilio se promulgaron sin ninguna restricción. La reflexión gramatical estaba destinada al latín, y al contrario de lo que acontecía en otros países, la lengua portuguesa no merecía tal consideración. Así, el latín continuó siendo, incluso durante el Renacimiento, la lengua de la ciencia. Ni siquiera se enseñaba en las escuelas la lengua materna, hecho que solamente se solventó en el siglo XVIII con las reformas pombalinas.

En Portugal, nos recuerda Sousa Viterbo (1915:155):

As linguas antigas, o grego e o latim, eram o vehiculo indispensavel de todo o ensino. Não só se lia por livros latinos e gregos, mas até o idioma do Lacio era a linguagem familiar dos estudantes. Era quase infamente, mesmo fóra das aulas, o falar-se a linguagem vernacula.

Añade interesantes datos sobre la situación preponderante del latín y la vergüenza que algunos escritores sentían si utilizaban su lengua propia. Era tal la importancia de la lengua culta que ofrece una lista de las gramáticas publicadas en latín durante el siglo XVI (entre 1502 y 1599) - un total de veinticuatro - frente a dos portuguesas. Se queja Sousa de que los elementos clásicos y extraños echaron profundas o extensas raíces en la educación de la 
mocedad portuguesa, contribuyendo a desnacionalizarla y dándole un carácter cosmopolita y universal. Se utilizaban temas de otras literaturas y se componía en otras lenguas, cual la española, pareciendo que "a lingua portugueza era desconhecida no inferno. Lisonjaria nacional dos nossos poetas!".

Ese furor por la defensa del latín como lengua culta para los asuntos serios en Portugal, llegó a tal extremo que Jerónimo Cardoso (autor del primer diccionario portugués-latín y latín-portugués):

No tenía pelos en la lengua, en 1563, al tildar el portugués de «habla grosera» y «lengua bárbara». Y no era el único humanista que menospreciaba la lengua natal. André de Resende, humanista de talla internacional, discípulo de Nebrija en Salamanca, confesaba por la misma época cierto desamor por la lengua vernácula, pues si su existencia dependiese de su voto, «podría en buena hora morir, con tal de que se cambiase por la Romana, que antaño tuvimos» (Gavilanes, 2000:39).

\title{
3.2. El bilingüismo literario. Penetración del castellano en la cultura de las clases letra- das portuguesas
}

En palabras de Sousa Viterbo (1915:160):

\begin{abstract}
Se as litteraturas classicas e a litteratura e scienzia francesa actuaram com tamanho poderio sobre a cultura nacional; se os escriptores italianos, já directamente, já por intermedio dos escriptores hespanhoes, nos seduziram com as suas bellezas e se nos impuseram como modelos; acima de tudo isto devemos collocar todavia a influencia da lingua e da litteratura hespanhola. A vizinhança, o contacto social e político; a communidade de procedencia; a promiscuidade das tradições historicas; a identidade de pensamentos e de aspirações; tudo isto nos explica o phenomeno.
\end{abstract}

\subsection{Orígenes del prestigio del castellano en Portugal}

Rafael Lapesa (1986:291-297) nos da abundantes razones que señalan la elevación del castellano a lengua internacional en la Europa de los siglos XVI y XVII, debido al prestigio de la política española en los Estados europeos y a la literatura castellana. Carlos V, Felipe II y Felipe III fueron los tres monarcas de la Casa de Austria que gobernaron en casi todo el mundo conocido, ampliando sus dominios a las nuevas tierras de América. Las monarquías europeas que no estaban sujetas al poder español adoptaron el castellano - en mayor o menor medida - como lengua de comunicación internacional ${ }^{4}$. En algunos lugares, dicha lengua sobrepasó la misión comunicativa y se convirtió en elemento literario, como fue Portugal.

\subsection{Razones literarias}

Ya hemos dejado entrever que, aunque fue a partir del siglo XVI cuando irrumpió con fuerza la lengua castellana en la expresión literaria y científica portuguesa, en el XV era

4 Se comenzó a aprender español por toda Europa y se necesitaban materiales. Véase al respecto el artículo de José Joaquín Martínez Egido: "La ironía: herramienta en la enseñanza del español como lengua extranjera (los diálogos del siglo XVII)”, en EULA 21 (2007), Universidad de Alicante, págs. 229-244. 
utilizada. El declive de la lírica medieval, la nueva poesía palaciega, la irrupción de la prosa al estilo castellano y la creciente preponderancia de España en política internacional, juntamente a la cantidad de reinas y princesas españolas que se casaban con reyes portugueses, propulsó que el castellano sirviese de modelo para la naciente literatura clásica portuguesa.

Tal y como declara Saraiva (1989:183):

Aos efeitos da contra-reforma vieram juntar-se, a partir de 1581, os da união com Espanha. Do primeiro resultou, como apontámos, murcharem as promessas do Humanismo. $\mathrm{O}$ segundo teve como consequência o desaparecimento da corte de Lisboa, o foco literário mais estimulante do país.

En este punto, muchos de los estudiosos del tema que nos ocupa no se ponen de acuerdo y tienen diferentes opiniones sobre la cuestión: algunos dicen que fue un hecho que engrandeció a Portugal, otros opinan todo lo contrario. Consideraremos a Prado Coelho (1978) y a Vázquez Cuesta (1981/1988) como las dos figuras que representan esas dos tendencias contrarias.

El primero en su Dicionário de Literatura (1978:108), al consultar la entrada 'bilinguismo' nos dice que se designa así al "facto de, entre o séc. XV e começos do séc. XVIII, haver numerosos autores portugueses que escreveram em castelhano". Continúa afirmando que el hecho, ubicado principalmente en el Renacimiento, coincide con el desarrollo autónomo del portugués como lengua literaria en la lírica y la prosa (siglos XVI-XVII), habiéndose iniciado en un período de plena afirmación de la personalidad nacional (descubrimientos, conciencia imperial, Gil Vicente, Camões). Parece que intenta justificar el hecho basándose en un estudio de João de Castro Osório ${ }^{5}$. Afirma que el fenómeno del bilingüismo es común a las literaturas europeas, se adopta una lengua extranjera más hecha, como instrumento de creación, más fácil, de una obra. Dice aún:

Os Portugueses preferiram o castelhano por ser língua esteticamente mais trabalhada (veja-se como Sá de Miranda ensaia em castelhano os primeiros passos na «medida nova») e de maior projecção europeia, além de razões secundárias, como a presença na corte portuguesa de rainhas e princesas espanholas ${ }^{6}$, a estadia de Portugueses em Espanha, a dominação filipina.

Justifica el hecho, como gran cantidad de autores portugueses, bajo la idea de que en Castilla, durante la Edad Media el gallegoportugués fue la lengua de la lírica. Al mismo tiempo señala que a pesar de todo, se intuye el genio portugués a través de los escritos españoles.

Para la filóloga gallega Pilar Vázquez Cuesta (1981/1988), es sorprendente y en cierta medida escandaloso que muchos estudiosos del período filipino justifiquen el hecho de que muchos escritores portugueses durante los siglos XVI y XVII escribiesen en castellano, alegando que ese bilingüismo no era nuevo, dado que al contrario también sucedía. Es decir, durante los siglos anteriores el gallegoportugués había sido la lengua de la lírica en Castilla,

5 (1942) Florilégio das poesias portuguesas escritas em castelhano e restituidas à lingua nacional, Ocidente, Lisboa. (Traduz o Condestável D. Pedro, outros poetas do Canc. Geral e Gil Vicente).

6 Desde la fundación de Portugal en 1139 como una Monarquía hasta la proclamación de la República en 1910, han reinado en el país vecino 34 monarcas. 17 de sus reinas fueron de origen español (sobre todo, en el período entre 1200 y 1600 ). 
con la figura de Alfonso X el Sabio como referente. Vázquez Cuesta apunta que la situación no era para nada comparable: el gallegoportugués no hizo peligrar en ningún momento al castellano como lengua de cultura, mientras que el castellano sí desplazó al portugués para el mismo cometido.

La influencia de la lengua y la cultura castellanas sobre Portugal remite a un período anterior al de la regencia de los Felipes y se extiende más allá de la Restauração. Vázquez Cuesta recuerda que la infiltración castellana, iniciada a mediados del siglo XV sirvió a los intereses de la clase dominante portuguesa que estuvo a punto de ocasionar una situación de diglosia que perduró hasta el final del siglo XVII. Nos vuelve a recordar que el castellano fue adoptado en Portugal como lengua de moda en la corte desde el reinado de don Afonso V (1438-1481), conserva su prestigio debido a las sucesivas reinas españolas que reinaron en Portugal y se consolida en el siglo XVI en la literatura.

Por otro lado, cuando don João III (1521-1557) reforma la enseñanza universitaria en Portugal (entre 1537 y 1547), manda venir a profesores de España, "servindo para aumentar ainda mais a provinciana admiração por tudo o que fosse espanhol que (...) experimenta o Portugal pré-filipino" (Vázquez Cuesta, 1988:42).

Si la incursión no hubiese parado después de la Restauração, quizá con el tiempo el castellano habría usurpado todos los estilos literarios portugueses. Por otro lado, y desde un punto de vista práctico, como observa Garcia Peres (1890:VIII):

Nadie ignora que la generalidad de los escritores portugueses escribieron en castellano para sus publicaciones por conveniencia de propaganda, visto que el conocimiento del portugués ha sido siempre en Europa rara, rarissima avis.

\subsection{Razones políticas}

Ya se han ido señalando varias causas políticas que propiciaron el prestigio de la lengua española en Portugal. Las principales se resumen en las siguientes:

a) la gran cantidad de reinas de origen español que se sentaron en el trono portugués -y que poco ayudaron en el cometido de mantener cierto respeto por la lengua del país de acogida-,

b) la imposición de dos instituciones religiosas venidas de España: la Santa Inquisición y la Compañía de Jesús y

c) la hegemonía política y militar de España en Europa.

\subsection{El bilingüismo como proceso diglósico}

Todas las razones hasta este momento descritas nos indican que aún existiendo voces disidentes en cuanto al uso del castellano en Portugal (Barros, Nunes de Leão y Gândavo, por ejemplo) el bilingüismo luso-castellano era ya un fenómeno ampliamente consolidado entre las clases portuguesas más cultas.

Ese proceso diglósico afectó a los escritores, pensadores e impresores. Nos dice Asensio (1951) que no era sólo la Corte la que favorecía la difusión del castellano, la propia literatura de cordel, los romances y refranes españoles se cantaban en lengua castellana por las calles de Lisboa. 
Por otra parte, la imprenta portuguesa revela esta moda. Se imprimió en castellano La Celestina, la Questión de Amor, las traducciones de la Fiammetta de Boccaccio, de la Parsalia de Lucano, del Enquiridión de Erasmo, de la Biblia, así como libros de arquitectura y poesía diversa. Nuno Fernandes do Cano tradujo los Proverbios de Salomón (1544) y en el prólogo dice así (Apud Asensio 1951:XLVII-XLVIII):

Podia me ser cõ rezam perguntado qual era a causa que sendo eu portugues, me conduzio a interpretar em outra e nam na nossa portuguesa e materna lingoagem: a resposta esta em prõto; por aquillo do philosopho: que a privaçam he causa de apetito: porque como quer que a castelhana nos nam seja tam familiar, paresce nos que para ho fastio he mais apetitosa que a nossa, ho que a mi assi nam paresce, antes creo que bẽ oulhado e posta esta altercada questam sub indice ( $\mathrm{sic}$ ), nam suspecto e considerados bem os fundamentos substanciais de hũa e outra oposiçam, que a nossa alcançaria ho brauio desta aposta, ho que com bem pouca logica antre bõs juyzos se podia bem determinar. A nossa em euphonia acẽto e ortografia he mais cõforme a latina... Desta opiniã creo que tambem sera o docto Joam de Barros, feitor da casa da India, bom preceptor da boa e verdadeira lingoagẽ portuguesa... Pollo que consta que quis eu mais satisfazer a gente plebea que ha minha opiniãm, o que assi foy necessario pera que mais limpamente podesse per mãos dos calcografos (que doutra maneira nam queriã) mandar a vossa senhoria essa pouca (inda que boa) fruita. (a V verso) ho Ecclesiastes foy jaa por bum Damiam de goes a vossa senhoria apresentado em nosso portugues.

En definitiva, el peso de la literatura española, de las circunstancias políticas y del prestigio del castellano

Llegó a ser tan aplastante en Portugal en el siglo XVI que, con excepción de António Ferreira, Frei Agostinho da Cruz, Jorge Ferreira de Vasconcelos y pocos más, un gran número de escritores portugueses, entre los cuales se encuentran Gil Vicente, Sá de Miranda y Luís de Camões escriben mayor o menor parte de su obra en lengua castellana (Gavilanes, 2000:40).

\subsection{Situación posterior a la Restauração (1640). Declive del bilingüismo. Barroco y Siglo de las Luces. Exaltación de la lengua nacional}

Para Teyssier (2001) los sesenta años de dominación española que se sitúan en el período más brillante del Siglo de Oro acentuaron la impregnación lingüística. Solamente después de 1640 , con la Restauração y la subida al trono de don João IV (1640-1656) se produjo una cierta reacción antiespañola. Pero el fin de la dominación política no significó el fin inmediato del bilingüismo, perdurará hasta la desaparición de los últimos representantes de la generación formada antes de 1640. De la misma opinión es Vázquez Cuesta (1988) al afirmar que se seguirán encontrando señales del bilingüismo hasta que no desaparezcan los representantes de las generaciones nacidas para la vida intelectual durante el período prefilipino.

En los años siguientes a la Restauração se fortalecieron los órganos constitucionales del poder y con ellos la dignificación de la lengua portuguesa. Ya en el siglo XVIII, don João V (1706-1750) hizo que Portugal reaccionase institucionalmente en relación con el problema de la defensa de la lengua, cuestión relacionada con el Imperio colonial. Desde Brasil llegaban noticias de que allí se hablaba un mal portugués y la culpa era achacada a los educado- 
res: los jesuitas. E1 rey adoptó varias medidas: se oficializó el uso de la lengua portuguesa. Esta reforma se consolidó con el rey don José I (1750-1777), a través de su primer ministro, el Marqués de Pombal (Sebastião José de Carvalho e Melo, primer ministro de 1756 a 1777). Finalmente, en 1770, mediante decreto real, la lengua portuguesa se instituye como lengua oficial y de enseñanza en las escuelas; también como lengua de las colonias.

Los antecedentes de estos hechos fueron los siguientes:

- Se produjo una reforma pedagógica propuesta por Luís António Verney ${ }^{7}$, autor que marcó el final del Barroco y el inicio de la época moderna en Portugal. El corte radical representado por sus ideas, en el Verdadeiro Método, provocaron reacciones contrarias entre algunos autores, como es el caso del jesuita José de Araújo que publicó en 1748 unas Reflexões Apologéticas ${ }^{8}$ donde critica la ortografía y la enseñanza de la lengua materna:

E que diremos de julgar, que se devem introduzir no Reino escolas para os rapazes aprenderem a Língua Portuguesa? Haverá esta moda em França? O homem tem boas ideias; é moda que pais gastem dinheiro para que os seus filhos falem. Nas escolas de ler, escrever e gramática tanto falam eles em português que amofinam aos mestres e é necessário castigá-los para que se calem. A nossa língua não é morta para que os naturais necessitem de tal diligência.

- La política de las colonias ejemplifica muy bien la situación institucional del portugués en ese período. No existía una política de expansión de la lengua, hecho que provocó que el portugués no fuese la lengua más hablada en los territorios portugueses americanos. En los centros urbanos se restringía al uso jurídico y la mayoría de la población hablaba la lingua geral do Brasil, es decir, el tupí - y en menor medida el guaraní-. Las escuelas existentes educaban en latín y la catequización de los indios se hizo en la lengua autóctona?

Aún querríamos añadir otro dato significativo que muestra la reacción antiespañola de la época: la reforma ortográfica establecida por la Academia de Lisboa en el siglo XVIII, en la que la tendencia etimológica se sobrepuso de modo definitivo a la tendencia foneticista, ha sido explicada como un reflejo de la influencia de la ortografía francesa, y a la vez, por el deseo de convertir a la lengua portuguesa, incluso en el plano gráfico, en una lengua cada vez más diferenciada de su vecina peninsular. Sólo a partir del siglo XX la ortografía portuguesa ha conseguido una norma más o menos estable ${ }^{10}$.

7 Publicó en 1746 el Verdadeiro metodo de estudar para ser util à Republica, e à Igrej.: Doutor na Universidade de Coimbra Tomo primeiro [segundo] Valensa [Nápoles]: na oficina de Antonio Balle.

8 Reflexoens/ apologeticas/à obra intitulada/ Verdadeiro/mehodo de estudar/Lisboa: na officina de Francisco Luiz Ameno, 1748.

9 La primera gramática de una lengua indígena brasileña fue publicada en Coimbra en 1595. Fue escrita por el misionero jesuita José de Anchieta y se titulaba Arte de Gramática da Língua mais Usada na Costa do Brasil. Se trata de una gramática al estilo occidental donde se sistematiza la lengua tupí. Paralelamente fue traducida a este idioma la Biblia.

10 La cuestión ortográfica es uno de los capítulos más atormentados de la historia lingüística portuguesa. Al contrario del español, que a finales del siglo XV encontró en Nebrija a su codificador tanto de la grafia como de la gramática, el portugués mantuvo hasta principios del XX una grafía tradicional inspirada en etimologías un tanto arbitrarias. La normativización precoz del castellano estaría relacionada con el estatuto de este idioma como lengua de cultura en la Península, y la normativización tardía del portugués estaría relacionada a su menor prestigio. 


\section{Romanticismo. Idea política de la Unión Ibérica}

El Iberismo - denominado también Unión Ibérica- es una doctrina política que propugna y defiende la intensificación de las relaciones de toda índole entre Portugal y España. Dicha intensificación es esencial en los campos económico y cultural. Ha tenido diferentes vertientes, destacando en el plano filosófico y literario escritores como Miguel de Unamuno, Teixeira de Pascoaes, Eça de Queirós, Oliveira Martins, Teófilo Braga, Antero de Quental, Maragall y Eduardo Pondal.

Para llegar a ese ideario en Portugal, hay que volver brevemente sobre los hechos acaecidos en 1640: tras la recuperación de la soberanía nacional, la reacción antiespañola no se hizo esperar. Portugal puso sus ojos en la cultura francesa como modelo. España y lo español eran vistos con recelo.

La situación parece que empezó a cambiar con la llegada a la Península de los ideales del Romanticismo. En ese contexto, un escritor catalán, Sinibaldo de Mas, publicó en 1851 un ensayo titulado La Iberia. Memoria sobre la conveniencia de la unión pacífica de Portugal y España. Su ideario fue asumido por determinados escritores portugueses y por los federalistas españoles. Se veía en un pasado cultural histórico común una fuerza para combatir la excesiva apatía intelectual y política en que vivían nuestros dos países. Así, en 1871 Oliveira Martins organizó una serie de conferencias públicas, bajo el lema: O problema do socialismo é esencialmente um problema de organização do trabalho. La sorprendente conferencia de Antero de Quental (las famosas Conferências do Casino) ostentaba el rótulo siguiente: Causas de decadência dos povos peninsulares nos séculos XVII e XVIII.

Uno de los puntos básicos del ciclo de conferencias de Oliveira Martins consistía en "ligar Portugal com a cultura europeia, fazendo-o assim nutrir-se dos elementos vitais de que vive a humanidade civilizada". Como existía una estrecha relación con grupos del movimiento obrero español, consideraron que debía consolidarse una federación de pueblos de la Península Ibérica. Los anarquistas crearon la Federación Ibérica en que militaban también los libertarios portugueses.

Desde el lado catalán ${ }^{11}$, nos recuerda Rodríguez Vega (2004:455-465):

A idea do iberismo agroma no seo dos grupos federalistas cataláns desenvolvida por teóricos como Romaní i Puigdengolas. No artigo de 1886 "El criterio de la Revista", onde se explican as liñas que deberán rexer a publicación de "La España Regional", Puigdengolas expón a idea de que unha descastelanización de España podería comportar a incorporación de Portugal ao conxunto peninsular. $O$ rexionalismo recolle deste xeito a idea federalista sobre o iberismo (só a aceptación da diversidade interna de España consentirá a incorporación de Portugal). [...] A división da Península en tres razas principais, en tres grandes nacións (a catalá, a castelá e a portuguesa) será, malia as precisións que se fagan sobre os outros grupos nacionais, a base do iberismo catalanista, o cal propón federar non os reinos históricos ou as rexións senón as nacións peninsulares. No "Pròleg al llibre català-portuguès d'en Ribera i Rovira" obsérvase xa a adhesión de Maragall ó enfoque iberista, presentando unha visión trimembre da península ibérica. Deste xeito o escritor supera a tradición federalista decimonónica que contemplaba a unión ibérica como unha federación dos antigos estados peninsulares e non como a unión de tres núcleos nacionais que se manteñen libres.

11 Véase: Martínez-Gil, Víctor (1997), El naixement de l'iberisme catalanista, Barcelona, Curial. 
La opinión de Maragall a ese respecto es la siguiente (del prólogo del libro arriba indicado):

Avui com avui, en la península hispànica per sobre o per sota de les fronteres o no fronteres polítiques, s'hi troben tres famílies nacionals ben definides en el seu parlar: la galaicoportuguesa, la castellana i la catalana, que ocupa també les illes Balears: són l'Espanya atlàntica, l'Espanya central, i l'Espanya mediterrània. Son tres zones geogràfiques, tres faixes verticals i paralleles de dalt a baix de la península hispana. Qui del reconeixement d'aquest fet natural en sabés i pogués arrencar tota una política peninsular, ben segur que donaria a Espanya la glòria $\mathrm{i}$ el benestar dels pobles que viuen en conformitat a la llei de la seva naturalesa.

En el resto de España la repercusión del iberismo fue menor. Excepto Miguel de Unamuno, no se pueden citar escritores con cierto rango. En la década de 1920 parecía extinguido el iberismo. Franco y Salazar intentarían una nueva aproximación con el Pacto Ibérico de "no agresión", firmado en Sevilla en 1940.

\section{Conclusión}

Parafraseando a Sousa Viterbo (1915), diremos que las sucesivas alianzas de familia entre las cortes española y portuguesa, las relaciones sociales y políticas e intereses comunes, eran poderosos elementos para que la civilización española ejerciese su hegemonia sobre la portuguesa. Si se añade 'a ello que España estaba en contacto directo con los más poderosos centros intelectuales de Europa: Italia, Flandes, Alemania y Francia, esta circunstancia bastaría para darle un lugar de superioridad. España atraía, ya que por intermedio de ella se volvían conocidos en el mundo culto, escribiendo en castellano, todos los escritores, fuesen de donde fuesen.

No obstante, aunque la mayoría de los críticos y estudiosos del bilingüismo español en Portugal aportan grandes estudios, todos coinciden en que todavía falta un trabajo profundo que sistematice la cuestión. Si, desde el punto de vista literario, el más trabajado, falta un estudio completo, no podemos menos que afirmar que desde el lexicográfico está todo por hacer al respecto.

Nuestro cometido inicial está íntimamente ligado al literario y científico. Si se escribe en castellano en Portugal - escritura literaria y científica - ¿dónde están los materiales de apoyo, los diccionarios?, piénsese que estamos en pleno Renacimiento, una época en la que la actividad lexicográfica es extraordinaria. Hallamos muy pocas respuestas que nos puedan ayudar en los trabajos leídos, no obstante, algunas tesis se perfilan como aclaratorias: una de ellas es la defendida por Vázquez Cuesta: Opina la catedrática gallega que el castellano que se escribía en Portugal devino en una especie de 'dialecto castellano' propio del país vecino; dialecto que se transmitía inmutable entre los escritores.

Por otro lado, Sousa Viterbo (1915:170) nos da pistas sobre el tema. Preferimos transcribir el párrafo para ver en toda su extensión la cuestión. Nos dice:

Muitos dos nossos escriptores manejaram perfeitamente a lingua hespanhola, principalmente os que residiram em Hespanha, mas os que nunca sahiram de Portugal apresentaram por vezes vicios patrios, verdadeiros provincianismos para bem dizer. [...] Faria e Sousa diz 
que muitos dos portugueses, que escreviam em castelhano, mostravam claramente que não sabiam nenhuma das duas linguas. Parece que os residentes em Castella se orgulhavam de possuir, como naturaes, o idioma estranho.

En todo caso, se nos hace extraño que no existan materiales lexicográficos. Salvo los diccionarios multilingües de los siglos XVI y XVII, el único compendio que contenía el español y el portugués era el Prosodia in vocabularium trilingue, Latinum, Lusitanicum, \& Hispanicum de Bento Pereira, publicado en 1634, seis años antes de la independencia. A partir de la $6^{\text {a }}$ edición de 1683 se sustituyó en el título el adjetivo Hispanicum por Castellanicum, y a partir de la $7^{\text {a }}$ edición, desaparece la lengua española, se insertan 24.000 voces latinas y la obra pasa a llamarse Prosodia in vocabularium bilingue latinum et lusitanum digesta. Mucho nos tememos que la desaparición de la lengua en esta edición tiene que ver con el declive del bilingüismo español en Portugal.

Como se observa, el panorama es bastante desolador. A pesar de ello, nuestro cometido va a discurrir por otros derroteros. Hemos intentado discernir las causas de esa ausencia de diccionarios en una época: para muchos escritores el castellano era una lengua casi litúrgica aprendida de literato a literato. Los grandes autores aprendían y perfeccionaban la lengua en España, lo cual pudo ayudarlos a manejarla perfectamente. Sin duda alguna debían mantener contacto con letrados españoles residentes en Portugal: recordemos que las universidades portuguesas estaban plagadas de profesores de aquí.

Una vez reconquistada la independencia (1640), se inicia el declive del bilingüismo en Portugal y la verdadera exaltación de la lengua propia con el Barroco que, adquiere su máximo nivel en el tiempo del rey D. João V (1706-1750) y el Marqués de Pombal. Se inicia una época de antipatía por todo lo español y de aproximación a todo lo francés.

Durante los doscientos años de alejamiento siguientes, únicamente se produjo una obra que confrontase las dos lenguas que nos ocupan: el Vocabulario portuguez e latino del padre Raphael Bluteau. El diccionario apareció en 1712, bajo los auspicios del rey don João $\mathrm{V}$, monarca ilustrado por excelencia. La obra de Bluteau contiene en el octavo volumen una 'Prosopopeia del idioma Portuguez a su hermana la lengua Castellana', una 'Tabla de palabras Portuguezas, remotas de la lengua castellana' y por fin un 'Diccionario Castellano, y Portuguez para facilitar a los castellanos el uso del Vocabulario Portuguez y Latino'. E incluso en esta obra podemos ver la influencia de la incipiente lexicografia española monolingüe inaugurada por Covarrubias (Azorín Fernández / Martínez Egido, 2006).

Los dos países se alejan y sólo será en 1864 cuando encontremos el primer diccionario bilingüe, el de Mascarenhas Valdez. A partir de ese momento la lexicografía en las dos lenguas, sea del lado portugués, sea del lado español es abundantísima y refleja claramente un tímido acercamiento de los dos países. Durante la segunda mitad del siglo XIX, un movimiento intelectual proiberista aboga por la unión federal de los dos países que forman la Península Ibérica. En esa efervescencia cultural se produce la aparición del primer diccionario bilingüe español-portugués.

\section{Referencias bibliográficas}

Alonso, Dámaso (1942), Tragicomedia de Don Duardos, Madrid, Consejo Superior de Investigaciones Científicas. Patronato Menéndez Pelayo. Instituto Antonio de Nebrija, tomo I, págs. 119-154. 
Alvar Ezquerra, Manuel (1995), «Los diccionarios del español», en Seco, Manuel y Gregorio Salvador [coord.], La lengua española, hoy, Madrid, Fundación Juan March, págs. 225-233.

Anchieta, José de (1595), Arte de Gramática da Lingua mais Usada na Costa do Brasil, António de Mariz, Coimbra.

Araújo, José de (1748), Reflexoens/ apologeticas/à obra intitulada/ Verdadeiro/ mehodo de estudar/ dirigida a persuadir hum novo/ methodo para em Portugal se ensinarem, e aprenderem as/ sciencias, e refutar o que neste Reino se pratica; : expendidas para desaggravo/ dos portuguezes em huma carta, que em repostal de outra escreveo da cidade de Lisboa para al de Coimbral o $P$. Frey Arsenio da Piedade... e offerecidas ao... Senhor D. Joaõ Joseph Ansberto de Noronha... por Niculao Francez Siom, Lisboa: na officina de Francisco Luiz Ameno.

Asensio, Eugénio (1951), "Prologo", in Jorge Ferreira de Vasconcellos Comedia Eufrosina, Madrid, Consejo Superior de Investigaciones Científicas. Patronato Menéndez Pelayo. Instituto Miguel de Cervantes, Biblioteca hispano-lusitana, págs. XL-LII.

Azorín Fernández, Dolores (2000), Los diccionarios del español en su perspectiva histórica, Alicante, Universidad de Alicante. (Monografías).

Azorín Fernández, Dolores y Martínez Egido, José Joaquín (2006), "Covarrubias en la lexicografía plurilingüe europea (siglos XVI y XVIII)" en Caminos Actuales de la Historiografia Lingüistica, Actas del $V$ Congreso Internacional de la Sociedad Española de Historiografia Lingüística, Murcia, 7 - 11 de noviembre de 2005, Antonio Roldan y otros (eds.), Universidad de Murcia, 2006, págs. 249-262.

Barros, João de (1540), Grammatica da lingua portuguesa, Olyssipone: apud Lodouicum Rotorigiu[m].

Bluteau, Raphael (1712-1721), Vocabulario Portuguez e Latino, Aulico... autorizado com exemplos dos melhores escritores portuguezes, e latinos, e offerecido a El Rey de Portugal, D. Joá̃ V pelo padre D. Raphael Bluteau, Coimbra, No Collegio das Artes da Companhia de Jesu.

Carta-patente dada por Filipe II em Lisboa, 12/11/1582 (compromisso do uso oficial da língua portuguesa na correspondência régia e nos diplomas referentes a Portugal).

Castro Osório, João de (1942), Florilégio das poesias portuguesas escritas em castelhano e restituídas à lingua nacional, Ocidente, Lisboa.

Cidade, Hernâni (1948), A literatura autonomista sob os Filipes, Lisboa, Sá da Costa, (NB. ver crítica de E. Asensio, Estudios, 1974, págs. 455-493).

Correia Fernandes, M. (1986), Literatura Portuguesa em Espanha. Ensaio de uma bibliografia (18901985), Porto, Livraria Telos Editora, Lda.

Ettinger, Stefan (1989-1991), "Die zweisprachige Lexikographie mit Portugiesisch", en Wörterbücher: Ein internationales Handbuch zur Lexicographie/Dictionaries: An international Encyclopaedia of lexicography/Dictionnaires: Encyclopédie internationale de lexicographie, Hausmann, Reichmann, Wiegand y Zgusta [eds.], 3 volúmenes, Berlín y Nueva York, De Gruyter, págs. 3.020-3.030, 3r volumen, (1989-1991).

Garcia Peres, Domingo (1890), Catálogo razonado biográfico y bibliográfico de los autores portugueses que escribieron en castellano, Imprenta del Colegio Nacional de Sordo-Mudos y de Ciegos, Madrid.

Gavilanes, José Luis, "La lengua portuguesa", en Gavilanes, José Luis y Apolinário, Antonio [eds.] (2000), Historia de la literatura portuguesa, Madrid, Cátedra, págs. 27-43.

Hermano Saraiva, José (1998[19 ed.]), História concisa de Portugal, Mira-Sintra, Publicações EuropaAmérica, Lda. (1 ${ }^{a}$ ed. 1978).

Jorge, Ricardo (1921), A intercultura de Portugal e Espanha no passado e no futuro, (prólogo de Carolina Michaëlis de Vasconcelos), Porto.

Lapesa, Rafael (1986), Historia de la lengua española, Madrid, Gredos, Biblioteca Románica Hispánica, Manuales $45,6^{\text {a }}$ reimpresión de la $8^{\mathrm{a}}$ edición.

Lemos, Maria Luísa (1985), A literatura autonomista no século XVII através do códice 29 da Biblioteca Geral da Universidade, (separata del Boletim da Biblioteca da Universidade de Coimbra, v. XL), Coimbra, Publicações da Biblioteca Geral da Universidade. 
Martinez Almoyna y Vieira de Lemos, A. (1968), La lengua española en la literatura portuguesa, Madrid, Imnasa, (Prólogo de Luís de Pina).

Martínez Egido, José Joaquín (2002), La obra lexicográfica de Lorenzo Franciosini : vocabulario italiano-español, español-italiano (1620), tesis doctoral. Biblioteca virtual Miguel de Cervantes, http://www.cervantesvirtual.com/FichaObra.html?Ref=7570. Universidad de Alicante.

Martínez Egido, José Joaquín (2006) La Lexicografia bilingüe y plurilingüe de los siglos XVI y XVII. E-Excellence: Lengua española, Liceus, Madrid (2006) [htpp://www.liceus.com/cgi-bin/aco/len/ temas_II.asp\#lexicologia].

Martínez Egido, José Joaquín (2007), "La ironía: herramienta en la enseñanza del español como lengua extranjera (los diálogos del siglo XVII)", en EULA 21, Universidad de Alicante, págs. $229-244$.

Mas y Sanz, Sinibaldo de (1851), La Iberia. Memoria sobre la conveniencia de la unión pacifica de Portugal y España, Typ. Universal, Lisboa.

Mascarenhas Valdez, Manuel do Canto e Castro (1864-66), Diccionario español-portugués el primero que se ha publicado con las voces, frases, refranes y locuciones usadas en España y Américas Españolas, en el lenguaje comun antiguo y moderno, Lisboa, Imprensa Nacional.

Nebrija, Elio Antonio de (1492), Gramática de la lengua castellana, Salamanca.

Oliveira, Fernão de (1536), Grammatica da lingoagem portuguesa, [Fernão Doliueira], em Lixboa: e[m] casa d'Germão Galharde, 27 Ianeyro 1536.

Pereira, Bento (1634), Prosodia in vocabularium trilingue, Latinum, Lusitanicum, \& Hispanicum digesta... / Authore Benedicto Pereyra..., Fecit sumptus Dominicus Pereyra da Sylva..., Eboræ: apud Emmanuelem Carvalho. [A partir de la $6^{\text {a }}$ edición de 1683 se sustituyó en el título el adjetivo Hispanicum por Castellanicum. A partir de la $7^{\text {a }}$ edición, desaparece la lengua española, se insertan 24.000 voces latinas y la obra pasa a llamarse Prosodia in vocabularium bilingue latinum et lusitanum digesta.]

Pinto Ribeiro, João (1730), "Uzurpaçaõ retençaõ e restauraçaõ de Portugal”, en Obras Várias, Coimbra, Oficina de José Antunes da Silva, Parte segunda.

Prado Coelho, Jacinto (1978[3 $3^{\mathrm{a}}$ ed]), Dicionário de Literatura, Porto, Liv. Figueirinhas (art. "Bilinguismo",v.I, p. 108-110).

Quental, Antero de (1871), Causas da decadencia dos povos peninsulares nos ultimos tres seculos, Typ. Comercial, Porto.

Rodríguez Vega, Rexina (2004), "Curros e a Renaixença catalá" en Actas do I Congreso Internacional 'Curros Enrique e o seu tempo', Consello da Cultura Galega, Santiago de Compostela, págs. 455-465.

Saraiva, António José / Lopes, Óscar (1989), História da Literatura Portuguesa, Porto, Porto Editora. $\left[15^{\mathrm{a}}\right.$ ed. corrigida e aumentada].

Sousa Viterbo (1915), A litteratura hespanhola em Portugal, Lisboa, (en História e Memórias da Academia das Ciências, nova série, $2^{\mathrm{a}}$ classe, t. XII).

Teyssier, Paul (1959), La langue de Gil Vicente, Paris, Librairie C. Klincksieck.

Teyssier, Paul (2001[8 $8^{a}$ ed.]), História da Lingua Portuguesa, Livraria Sá da Costa Editora, Lisboa.

Vázquez Cuesta, Pilar (1981), "O bilinguismo castelhano-português na época de Camões", en Arquivos do Centro Cultural Português, vol. XVI, Paris, págs. 807-827.

Vázquez Cuesta, Pilar (1988), A lingua e a cultura portuguesas no tempo dos Filipes, Lisboa, EuropaAmérica, (traducción del original "La lengua y la cultura portuguesas en el siglo del Quijote", en Historia de España de Menéndez Pidal, Madrid, Espasa Calpe, 1986).

Verney, Luís António (1746), Verdadeiro metodo de estudar para ser util à Republica, e à Igreja: proporcionado ao estilo, e necesidade de Portugal. Exposto em varias cartas, escritas polo $R$. $P$. *** Barbadinho da Congregasam de Italia, ao $R . P * * *$ Doutor na Universidade de Coimbra Tomo primeiro [segundo] Valensa [Nápoles]: na oficina de Antonio Balle [Gennaro e Vincenzo Muzio]. 